\title{
Plano da expressão musical: níveis de descrição ${ }^{1}$ \\ Peter DIETRICH (Doutorando, FFLCH-USP)
}

RESUMO: este trabalho propõe uma nova estruturação para o plano da expressão musical a partir da construção de níveis de descrição. Uma vez estabelecidos, eles servirão de ponto de partida para a reorganização de alguns aspectos do modelo atual, apontando para uma possível ampliação de sua abrangência, especialmente no campo de intensidades e timbres.

PALAVRAS-CHAVE: música, canção, semiótica.

RÉSUMÉ: ce travail propose une nouvelle structure de plan d'éxpression musical a partir de la construction de niveaux de déscrition. Une fois établis, ils constitueront le point de départ pour une réorganization de certains aspects du modèle actuel, ce qui nous permetra un enlargement de son apareil descriptif, surtout les questions d'intensités et timbres.

MOTS-CLÉS: musique, chanson, sémiologie.

\footnotetext{
${ }^{1}$ Este artigo desenvolve algumas idéias do trabalho "Semiótica do discurso musical" apresentado em maio de 2005 no $15^{\circ}$ Inpla (PUC-SP) e do trabalho "Semiótica do discurso harmônico: acorde, nota, melodia" apresentado em setembro de 2005 no IV Mini Enapol de Semiótica (USP)
} 
O primeiro fato a ser levado em conta para a estruturação de um plano da expressão musical é a possibilidade do estabelecimento de contrastes entre os seus elementos constituintes. Altura, intensidade, duração e timbre são, em uma primeira análise, as propriedades sonoras capazes de produzir estes contrastes. A partir dos contrastes estabelecidos por estas propriedades sonoras (atuando individualmente ou em conjunto) podemos perceber as transformações no decorrer do discurso musical. Podemos pensar ainda que estas quatro propriedades, projetadas no tempo, podem ainda estabelecer uma quinta: a densidade. Temos então a possibilidade de contrastes entre densidades rarefeitas (poucos instrumentos ou poucas notas atuando em um espaço de tempo) ou densidades concentradas. Neste trabalho, utilizaremos as canções Garota de Ipanema $^{2}$ (Jobim e Vinícius) e Paratodos ${ }^{3}$ (Chico Buarque) para mostrar a atuação destes elementos no plano da expressão musical.

As transformações de estado mais claras no discurso musical são transmitidas sobretudo por aquilo que o músico chama de "forma". A forma é a estrutura geral de uma peça. Em um standart de jazz, por exemplo, temos uma forma de 32 compassos, geralmente organizados em AABA. A canção Garota de Ipanema também tem essa mesma forma, apesar de não seguir o mesmo número de compassos. $\mathrm{O}$ ouvido consegue distinguir as partes de uma forma maior, e ele o faz exclusivamente pelo reconhecimento do contraste entre as partes. Ao ser exposto a uma parte, além de perceber todas as tensões internas, o ouvido passa a estabelecer relações entre esta primeira parte e as próximas. A primeira parte de uma peça é o peso e a medida para a apreensão do restante.

A liberdade que o discurso musical tem para marcar a passagem de uma parte a outra é enorme. Na imensa maioria das vezes, o principal contraste se dá entre alturas e durações - o que genericamente chamamos de "melodia". Quando nomeamos uma parte de "A" e outra de "B", estamos geralmente diante de uma mudança melódica substancial. A re-exposição de uma mesma melodia (idêntica ou pouco alterada) é musicalmente identificada como uma mesma parte. As pequenas variações são então marcadas como A', B', e assim sucessivamente. No entanto, é importante salientar que não há nenhuma razão para desconsiderar as repetições das partes de uma peça na construção do sentido global. Isso seria tão absurdo como dispensar um dos nove quadrantes da famosa obra de Andy Warhol com dez repetições da imagem de Marilyn Monroe (10 Marilyns, 1967) - já que cada um deles é uma variação de uma mesma imagem. Além do mais, apesar de geralmente apresentarem melodias idênticas, as repetições de uma mesma parte costumam ser marcadas pela introdução de novos contrastes - especialmente timbres, intensidades e densidades. Todas essas informações contribuem para a construção do sentido de uma peça.

Uma rápida e superficial análise da canção "Paratodos", de Chico Buarque, é suficiente para perceber como os timbres, intensidades e densidades podem marcar a passagem de uma exposição à outra. Elaborada com uma forma não usual (ABAAABA), com pouquíssima variação melódica entre as partes $\mathrm{A}$ e B, esta canção

\footnotetext{
2 Jobim, A. C. e Moraes, V. "Garota de Ipanema”, Jobim Music Ltda. e Tonga (BMG Music Publishing Brasil), 1961

${ }^{3}$ Hollanda, C. B. "Paratodos", Marola edições musicais Ltda, 1993
} 
evolui principalmente graças à instrumentação. Nesta transcrição, apresentaremos a indicação da parte (A ou B), os primeiros versos (apenas para localização), e os instrumentos percebidos.

$$
\begin{aligned}
& \text { A "meu avô era paulista": violão + baixo (seguem por toda a música) } \\
& \text { B "foi Antônio Brasileiro": + flauta + piano (fraco) } \\
& \text { A "nessas tortuosas trilhas": + percussão + piano (médio) - flauta } \\
& \text { A "vi cidades, vi dinheiro": + percussão + piano (forte) + flauta } \\
& \text { A "para um coração mesquinho": (piano e flauta mais ativos) } \\
& \text { B "viva Erasmo, Bem, Roberto": flauta + percussão + caixa + sanfona } \\
& \text { A "o meu pai era paulista": + cordas }
\end{aligned}
$$

Em "Paratodos", o contraste melódico entre as partes A e B é mínimo - as mudanças mais significativas são de timbre (percebidas pelo acréscimo de instrumentos), intensidade e densidade (esta última percebida principalmente graças a uma maior atuação de cada instrumento). No caso da Garota de Ipanema, temos um contraste essencialmente melódico (é assim na maioria das canções). Em primeiro lugar, há um significativo aumento na duração das notas da segunda parte. Além disso, há uma inversão na direção das gradações: descendentes na primeira parte, ascendentes na segunda. Por último, temos uma modulação (mudança de tom) marcando a entrada da parte B. A transcrição completa da canção está no Anexo 1.

A simples constatação de que um tema é composto por partes menores (no caso, partes A e B) é suficiente para estabelecer ao menos dois níveis de descrição hierarquicamente definidos: o tema, no nível superior, é composto de partes, elementos do nível imediatamente inferior. Podemos imaginar sucessivas decomposições deste nível inferior, até chegar à mínima unidade musical: a nota.

Cada nota é formada a partir das quatro propriedades do som: altura, duração, intensidade e timbre. Podemos fazer uma analogia com os femas, traços distintivos que definem os fonemas - e que não constituem um nível de análise. Assim como os fonemas são constituídos por um feixe de femas, as notas são formadas por um feixe de propriedades sonoras simultâneas. Assim como não há um fonema que seja apenas / sonoro /, não existe nota que tenha apenas altura ou duração. Não podemos então falar em um nível das propriedades do som: a nota é o limite da forma musical ${ }^{4}$.

As notas são as unidades constitutivas do segundo nível, o do intervalo. Os intervalos formam as células ritmo-melódicas, ou motivos. A junção dos motivos forma a frase, e o conjunto de frases forma a parte. $\mathrm{O}$ conjunto das partes forma aquilo que o músico costuma chamar de "tema", que é simplesmente a melodia inteira da canção. Em uma peça erudita, este nível seria chamado de movimento: a obra toda seria então um conjunto de movimentos. Podemos visualizar esta hierarquia em uma tabela:

\footnotetext{
${ }^{4}$ cf Lopes, E. "Fundamentos da lingüística contemporânea", São Paulo, Ed Cultrix s/d, pp. 50-55.
} 


\begin{tabular}{|l|l|}
\hline & Tema (Movimento) \\
\hline Nível 5 & Parte \\
\hline Nível 4 & Frase \\
\hline Nível 3 & Motivo \\
\hline Nível 2 & Intervalo \\
\hline Nível 1 & Nota \\
\hline & Propriedades do som (altura, duração, intensidade, timbre) \\
\hline
\end{tabular}

Tabela 1

Podemos agora encontrar o lugar reservado a cada um dos elementos elencados por Tatit na construção de seu modelo ${ }^{5}$. Tematização e passionalização são descritos como projetos entoativos de concentração e extensão, respectivamente. No primeiro caso, surgem os mecanismos de involução (tematização e refrão) e evolução (desdobramento e segunda parte). No segundo, os movimentos conjuntos (graus imediatos e gradação) e disjuntos (salto intervalar e transposição).

Graus imediatos e saltos intervalares são fenômenos pertinentes ao segundo nível, o do intervalo. Eles manifestam diretamente o estado tensivo da categoria juntiva: quanto menor o intervalo, maior a percepção de conjunção. $O$ ouvido percebe a diferença entre as freqüências de cada uma das notas de um intervalo: intervalos maiores exigem um maior esforço de transformação da onda sonora. Da mesma maneira, direções descendentes sugerem repouso, assim como inflexões ascendentes apontam para um aumento da tensão. A oposição se dá então na medida da velocidade desta inflexão: lenta nos graus imediatos, acelerada nos saltos intervalares. No final da parte B de Garota de Ipanema temos neste nível um elaborado jogo de tensões:

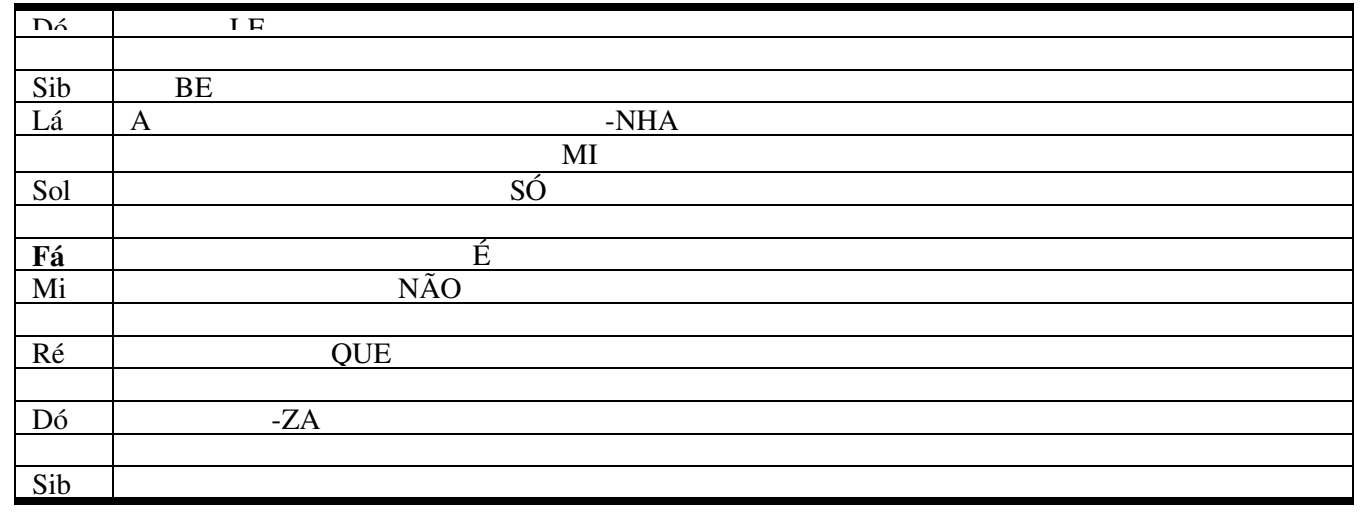

\footnotetext{
5 cf Tatit, L. A. M. "Musicando a Semiótica”, São Paulo, Ed Annablume, 1997, pp. 95, 96.
} 


\begin{tabular}{|c|c|c|c|}
\hline & & nó & \\
\hline & & Sib & QUE \\
\hline & & Lá & \\
\hline & & Sol & -NHA \\
\hline & & & $-\mathrm{ZI}$ \\
\hline & & Fá & SO \\
\hline & & $\mathrm{Mi}$ & $-\mathrm{SA}$ \\
\hline & & Ré & PAS \\
\hline & & Dó & -BÉM \\
\hline & & & \\
\hline & & Sib & TAM \\
\hline
\end{tabular}

A perda abrupta de tensão melódica em "a bele-za" e "que tam-bém" é retomada gradualmente por uma frase em graus conjuntos, que chegam até a "se espremer" em uma cromática no final "que não é só mi-nha que” e "pas-sa so-zi-nha".

Tematização e desdobramento são fenômenos que ocorrem no terceiro nível: eles dependem diretamente da organização dos motivos. A repetição dos motivos gera a tematização, enquanto a alternância produz o desdobramento. $\mathrm{Na}$ primeira frase de Garota de Ipanema, podemos ver como esse processo se desenvolve ritmicamente:

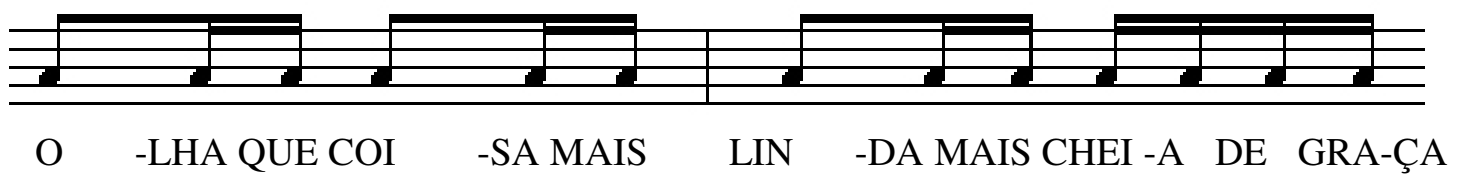

A repetição dos três primeiros motivos é uma tematização. A apresentação do último é um desdobramento. Neste primeiro trecho, a melodia também se repete. Temos uma tematização ao mesmo tempo rítmica e melódica. Muitas canções apresentam uma tematização parcial, mantendo o ritmo mas alterando a melodia - ou vice-versa. Outras utilizam técnicas mais complexas de espelhamento e movimentos retrógrados. Em todos os casos, o ponto em questão é o tratamento de informação já apresentada, com ou sem transformação. Isso afeta diretamente a percepção da categoria juntiva: de um modo geral, quanto maior for a redundância, tanto maior será a percepção de conjunção.

Gradações e transposições são fenômenos do quarto nível. Neste caso, o processo é muito semelhante ao de graus conjuntos e saltos intervalares, mas amplitude 
a ser considerada é substancialmente maior. Gradações representam movimentos com transição tensiva lenta; transposições são movimentos mais acelerados. Elas também podem ser ascendentes e descendentes, e têm o poder de aumentar ou diminuir a curva tensiva. Na segunda parte de Garota de Ipanema temos uma gradação ascendente responsável pelo acúmulo de tensão nas três primeiras frases:

Ah, porque estou tão sozinho

Ah, porque tudo é tão triste

Ah, a beleza que existe

Uma gradação descendente libera esta energia acumulada, ainda na parte B:

A beleza que não é só minha

Que também passa sozinha

Finalmente, segunda parte e refrão são fenômenos do quinto nível, e se comportam de maneira semelhante aos do terceiro nível. $\mathrm{O}$ refrão é uma tematização de alcance global. Guardadas as proporções, a segunda parte age como um desdobramento. No nosso exemplo, a repetição da parte A tem o efeito de um refrão. Todos estes procedimentos podem ser observados já hierarquizados na tabela 2:

\begin{tabular}{|c|c|c|}
\hline Nível 5 & Parte & $\begin{array}{c}\text { Refrão } \\
\text { Segunda parte }\end{array}$ \\
\hline Nível 4 & Frase & $\begin{array}{c}\text { Gradações } \\
\text { Transposições }\end{array}$ \\
\hline Nível 3 & Motivo & $\begin{array}{c}\text { Tematização } \\
\text { Desdobramento }\end{array}$ \\
\hline Nível 2 & Intervalo & $\begin{array}{c}\text { Graus imediatos } \\
\text { Saltos intervalares }\end{array}$ \\
\hline
\end{tabular}

Tabela 2

A distribuição dos procedimentos analíticos em níveis hierarquizados não é novidade na literatura da semiótica da canção. Na análise de "O que será", o próprio Tatit propõe uma análise escalonada para descrever o desenvolvimento melódico:

Temos, assim, um primeiro nível de elaboração: pequenas unidades entoativas alinhavam todo o percurso da canção num estrato figurativo primário (...). A cristalização do ritmo (duração) e do perfil melódico desses dois motivos, ou seja, sua imutabilidade nesses níveis, transforma-os em unidades coesas suscetíveis de serem manobradas e opostas entre si em outro estrato de significação mais amplo. ${ }^{6}$

${ }^{6}$ Tatit, L. A M. “O cancionista - composição de canções no Brasil”. São Paulo, Edusp, 1996, p. 255 
E, pouco mais adiante:

Em resumo, combinando as unidades interrogativas - que assinalavam um primeiro estrato de significação em nível figurativo - em seus diferentes níveis de freqüência, Chico obteve um segundo estrato de significação em termos de caracterização melódica de um núcleo passional disjuntivo. Em outras palavras, seus motivos figurativos estavam a serviço de um programa passional mais amplo. ${ }^{7}$

As "pequenas unidades entoativas" são unidades do terceiro nível (motivo). O nível imediatamente superior é o nível da frase (neste exemplo, formado pela junção dos dois motivos "figurativos"). É interessante notar que é só no nível da parte (formado pelas frases) é que podemos perceber a distribuição das frases ao longo da tessitura, gerando o efeito de passionalização a que Tatit faz referência.

Assim como na linguagem verbal, podemos pensar em relações distributivas e integrativas, e estabelecer no discurso musical as mesmas relações de forma e sentido propostas por Benveniste, tomando como base os níveis aqui estabelecidos. Desta maneira, um nível se define "pela sua forma, quando o encaramos na perspectiva que parte dele e se orienta na direção do nível que lhe é imediatamente inferior", e "por seu sentido, quando o encaramos na perspectiva que parte dele mesmo e se orienta na direção do nível que lhe é imediatamente superior".

Edward Lopes afirma que:

“(...) nenhuma unidade lingüística se satura - ou seja, se define como um significado unívoco e perfeitamente acabado -, no interior do seu mesmo nível: a significação é uma relação, uma estrutura elementar formada por dois elementos que contraem ligação, pertencentes, ambos, a níveis diferentes"."

Relações entre dois níveis diferentes são relações integrativas. Dentro de um mesmo nível, temos apenas relações distributivas. Ao comparar as duas "unidades entoativas", dentro do nível motívico, podemos apenas perceber seu contraste (assim o faz Tatit). A percepção de um bloco autônomo, formado pelas duas unidades (os dois motivos) só é possível no nível da frase. Da frase para o motivo, temos uma descrição da forma. Do motivo para a frase, o sentido. Passando para outro "estrato de significação", é somente a partir de uma nova relação integrativa, passando da frase à parte, é que podemos perceber o surgimento do efeito de sentido de passionalização.

É importante salientar que o enfoque no campo das alturas e durações é sempre uma escolha analítica. Por mais que possamos fazer uma descrição abstrata de uma

\footnotetext{
${ }^{7}$ idem, p. 258

${ }^{8}$ Benveniste, E. "Problèmes de Linguistique Générale". Paris, Gallimard, 1666, pp. 126-127

${ }^{9}$ Lopes, E. "Fundamentos da lingüística contemporânea", São Paulo, Ed Cultix s/d, p. 51
} 
melodia apenas com alturas e durações, ela jamais existirá sem intensidade e timbre. $\mathrm{O}$ fato de não existir ainda um lugar para o timbre e a intensidade no modelo de semiótica da canção não é motivo válido para supor que estas duas propriedades sejam menos participativas na construção do sentido de uma peça musical (conforme mostrado na análise de "Paratodos"). O modelo não extrai informações destas propriedades simplesmente porque não foi feito para isso. No entanto, basta ouvir um pequeno trecho de qualquer sinfonia de Beethoven para perceber a atuação da intensidade na construção de contrastes entre frases compostas por notas com as mesmas alturas e durações. Ou então procurar qualquer método de orquestração e arranjo para perceber a importância que a tradição musical ocidental atribui à escolha e combinação de timbres.

Podemos pensar então que existe um intervalo de altura entre duas notas, mas também existe um "intervalo" de durações, intensidades e timbres. A passagem de uma nota a outra, de um intervalo a outro, de um motivo, frase ou parte a outra pode ser de continuidade (de alturas, durações, intensidades e timbres) ou de contraste. Em cada nível, podemos convocar qualquer uma destas propriedades (além da densidade) para estabelecer relações de continuidade ou descontinuidade (e estabelecer também relações integrativas entre os níveis).

A complexidade do discurso musical é notável. A análise que fizemos até agora não é mais que uma descrição linear dos elementos constituintes. No entanto, todos estes elementos contraem entre si relações mais complexas, relações que a teoria musical designa genericamente pelo nome de "harmonia". Além disso, temos que levar em conta que uma música raramente é composta por apenas uma melodia. Na maioria dos casos, ela é fruto de uma imensa polifonia de vozes interconectadas. Cada uma delas pode ser analisada independentemente, em seus diversos níveis, com suas harmonias internas, mas também se relacionam umas com as outras em uma complexa rede. O dispositivo que este trabalho apresenta é apenas o passo inicial para a conformação do plano da expressão musical - passo necessário para a compreensão desta linguagem sob a perspectiva da semiótica greimasiana.

\section{Bibliografia}

Benveniste, E. "Problèmes de Linguistique Générale”. Paris, Gallimard, 1666

Lopes, E. "Fundamentos da lingüística contemporânea", São Paulo, Ed Cultrix s/d

Tatit, L. A. M. "Musicando a Semiótica”, São Paulo, Ed Annablume, 1997

"O cancionista - composição de canções no Brasil". São Paulo, Edusp, 


\section{Anexo 1}

PARTE A (primeira exposição)

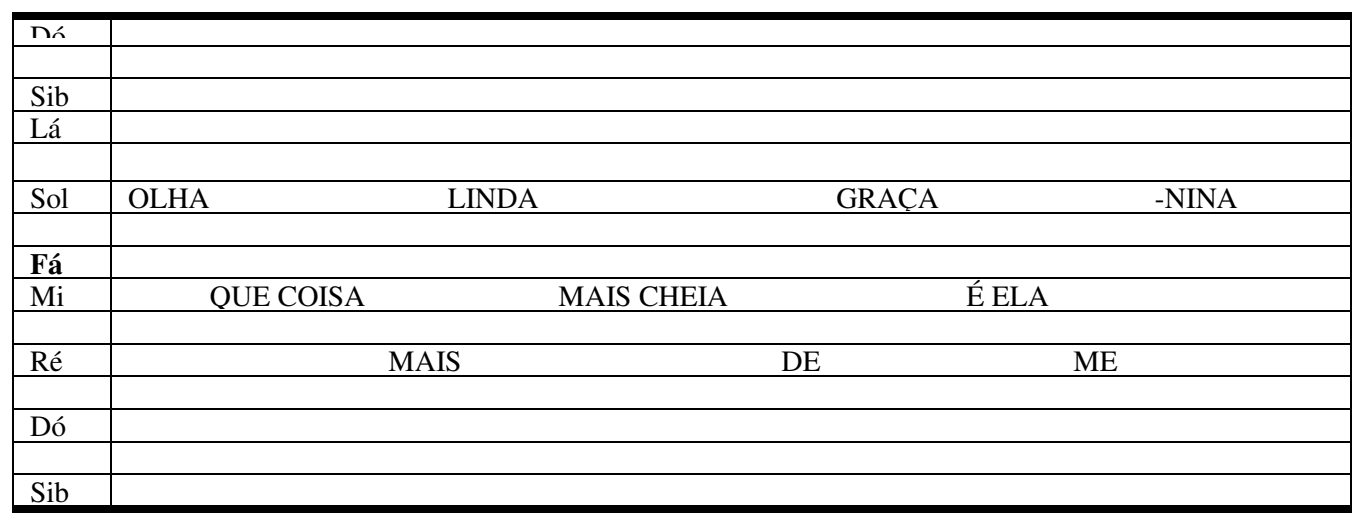

\begin{tabular}{|c|c|c|}
\hline חर́ & & \\
\hline $\mathrm{Sib}$ & & \\
\hline Lá & & \\
\hline Sol & & \\
\hline Fá & PASSA & \\
\hline $\mathrm{Mi}$ & QUE VEM E & -LANCQ A \\
\hline Ré & NUM DOCE & \\
\hline Dó & BA & CAMINHO MAR \\
\hline $\mathrm{Sib}$ & & DO \\
\hline
\end{tabular}




\section{PARTE A (segunda exposição)}

\begin{tabular}{|c|c|c|}
\hline nó & & \\
\hline \multicolumn{3}{|l|}{$\mathrm{Sib}$} \\
\hline \multicolumn{3}{|l|}{ Lá } \\
\hline Sol & MOÇA $\quad$-RADO & -NEMA $\quad$-CADO \\
\hline \multicolumn{3}{|l|}{ Fá } \\
\hline Mi & DO SOL DE I & O SEU BA \\
\hline Ré & $\mathrm{DOU}$ & -PA \\
\hline \multicolumn{3}{|l|}{ Dó } \\
\hline Sib & & \\
\hline
\end{tabular}

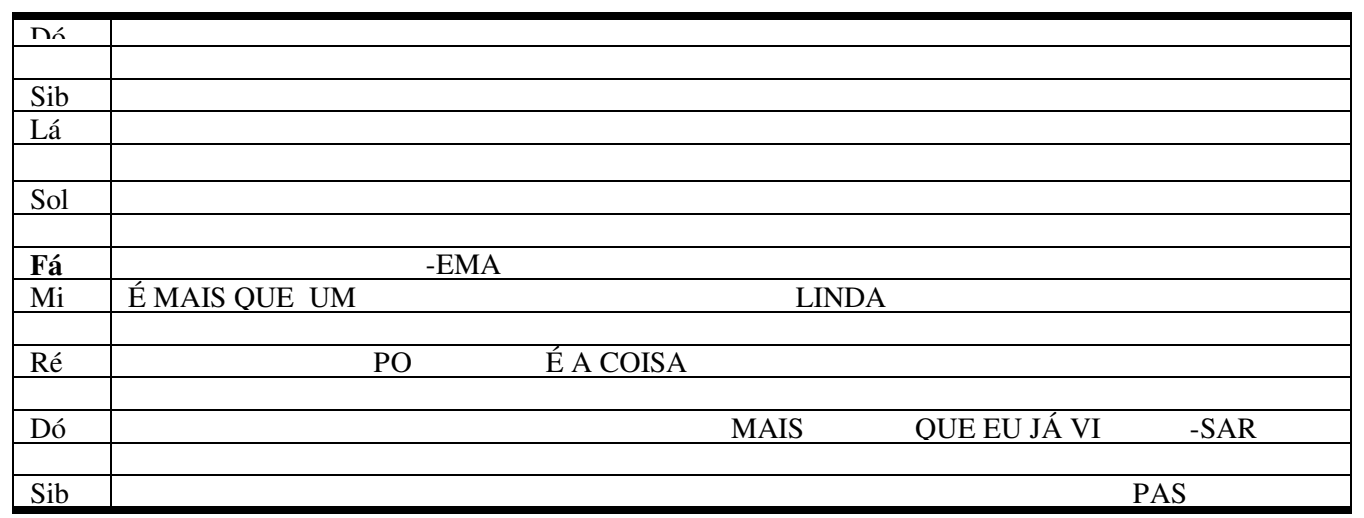




\section{PARTE B}

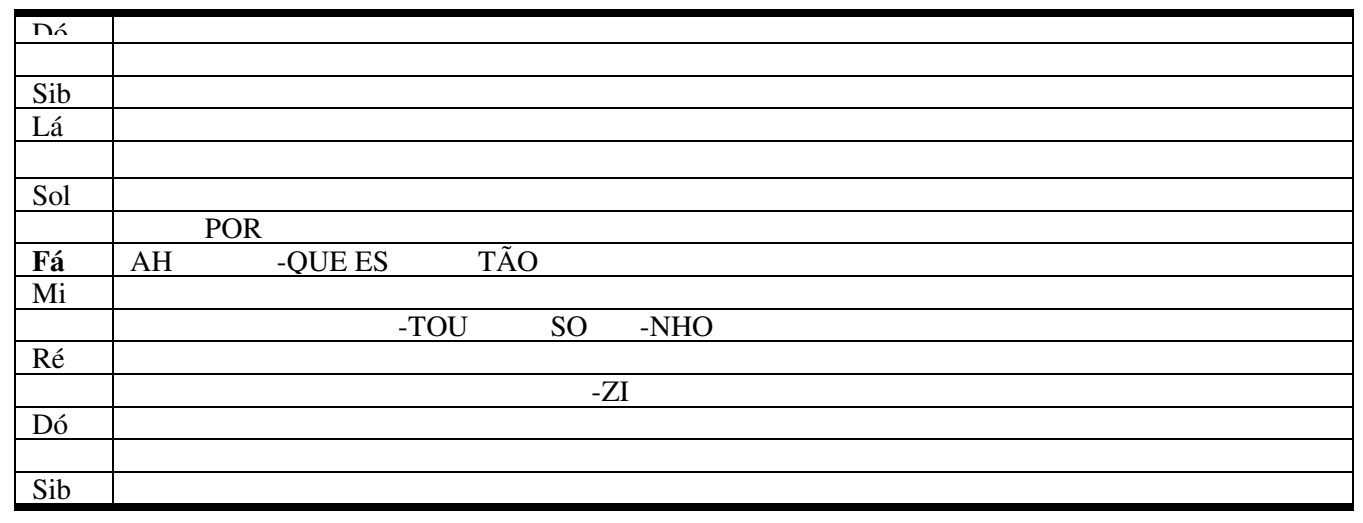

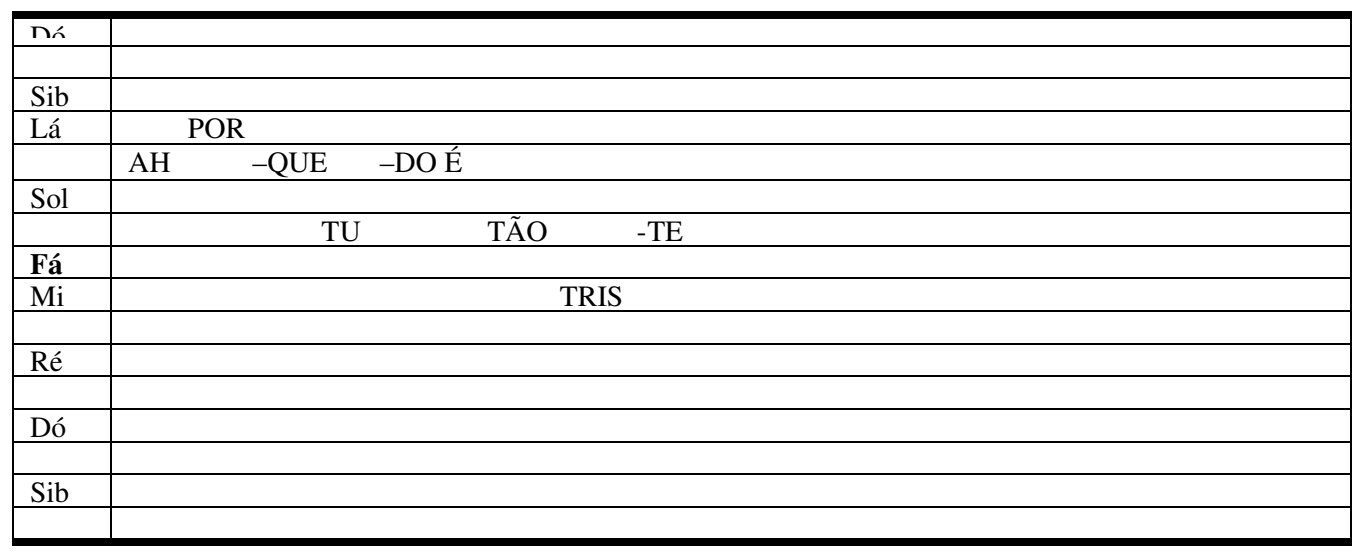




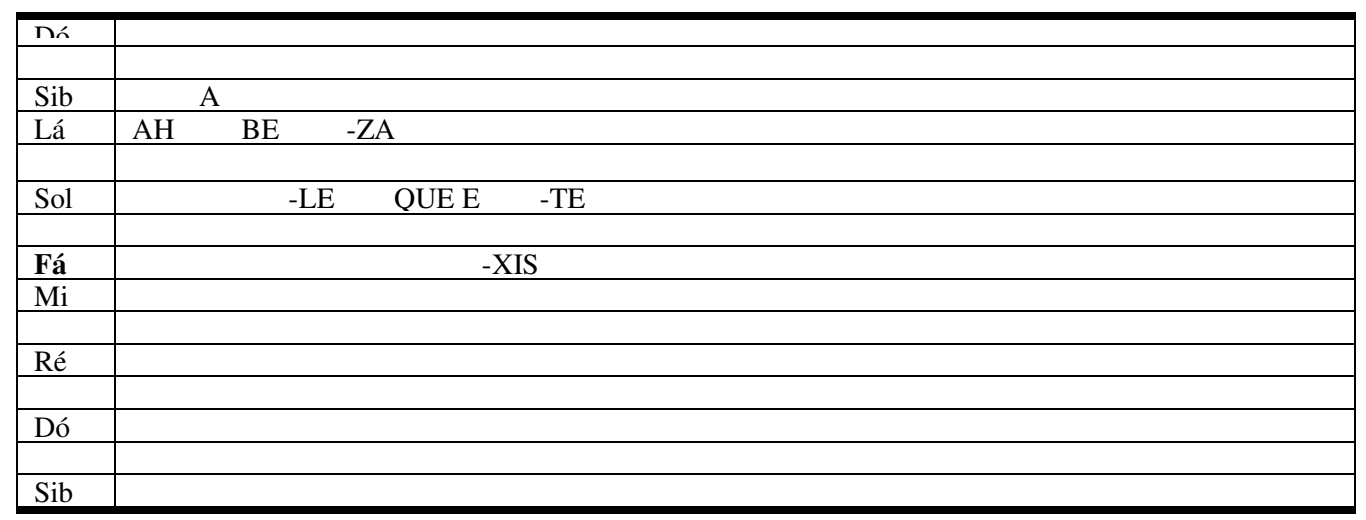

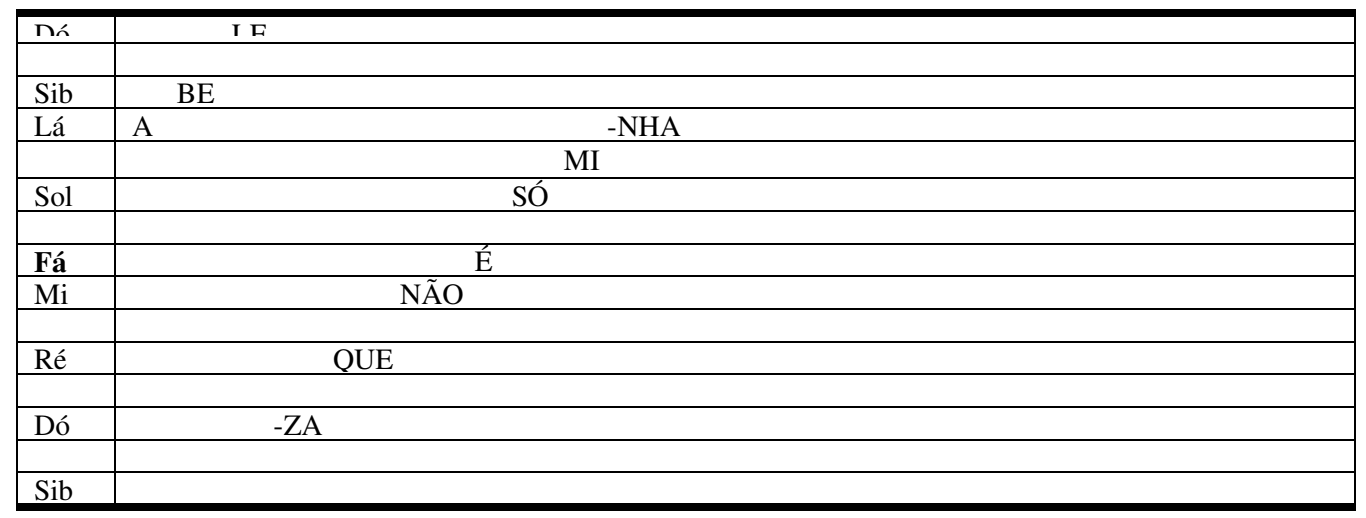

\begin{tabular}{|c|c|c|c|}
\hline & & nó & \\
\hline & & $\mathrm{Sib}$ & QUE \\
\hline & & Lá & \\
\hline & & Sol & -NHA \\
\hline & & & $-\mathrm{ZI}$ \\
\hline & & Fá & SO \\
\hline & & Mi & -SA \\
\hline & & Ré & PAS \\
\hline & & Dó & -BÉM \\
\hline & & $\mathrm{Sib}$ & $\bar{A}$ \\
\hline
\end{tabular}




\section{PARTE A' (terceira exposição)}

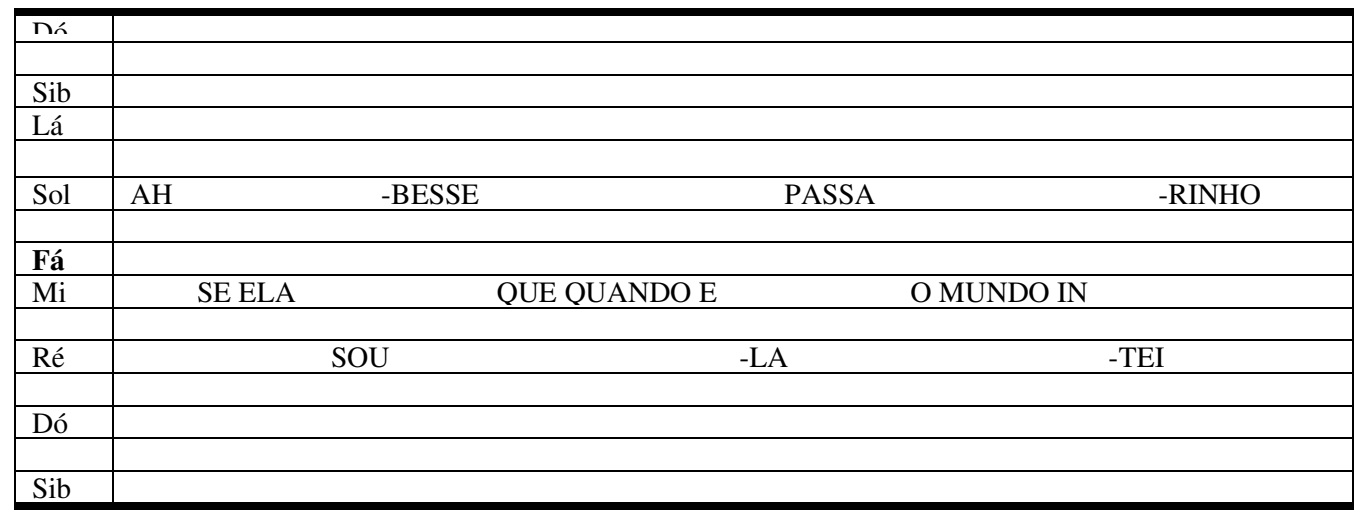

\begin{tabular}{|c|c|c|c|}
\hline$n \hat{n}$ & \multicolumn{3}{|c|}{ I INInn } \\
\hline \multicolumn{4}{|c|}{ Sib } \\
\hline Lá & \multicolumn{2}{|c|}{ GRACA } & \\
\hline \multicolumn{4}{|c|}{ Sol } \\
\hline Fá & \multicolumn{2}{|c|}{ E FICA } & \\
\hline $\mathrm{Mi}$ & SE ENCHE & POR CAUSA & -MOR \\
\hline Ré & $\mathrm{DE}$ & MAIS & \\
\hline Dó & & & \\
\hline Sib & & & \\
\hline
\end{tabular}

\section{Como citar este artigo:}

DIETRICH, Peter. Plano da expressão musical: níveis de descrição.

Estudos Semióticos, Número 2, São Paulo, 2006. Disponível em $<$ www.fflch.usp.br/dl/semiotica/es $>$. Acesso em "dia/mês/ano". 